\title{
Evaluation and follow-up of cognitive functions in patients with minor stroke and transient ischemic attack
}

This article was published in the following Dove Press journal:

Neuropsychiatric Disease and Treatment

16 August 2016

Number of times this article has been viewed

\author{
Çiğdem Deniz' \\ Yahya Çelik ${ }^{2}$ \\ Tuğçe Özdemir Gültekin' \\ Gozde Eryiğit Baran' \\ Çağla Deniz ${ }^{3}$ \\ Talip Asil' \\ 'Department of Neurology, Faculty of \\ Medicine, Bezmialem Vakıf University, \\ İstanbul, ${ }^{2}$ Department of Neurology, \\ Faculty of Medicine, Trakya University \\ Edirne, ${ }^{3}$ Department of Neurology, \\ Avrupa Hospital, Adana, Turkey
}

Background and purpose: We aimed to examine the incidence of cognitive impairment among patients with stroke, the associated risk factors, progression of the cognitive impairment, and the association between the localization of the lesion(s) as detected by magnetic resonance imaging and the affected areas of cognitive function.

Methods: A total of 40 patients over 18 years of age enduring a transient ischemic stroke or minor stroke within the past 3 months who had a minimum life expectancy of 1 year were included in this study. Same number, age-, and sex-matched individuals were included as controls. Patients were inquired on the presence of risk factors for stroke. A series of neuropsychological test batteries were administered in patient and control subjects for assessing cognitive functions. These tests were readministered at 6 and 12 months of follow-up to assess the progression of cognitive functions.

Results: In this study among the patients with stroke, a significant impairment was seen in multiple cognitive functional tests following ischemic stroke as compared to control groups. The most common risk factors for stroke included hypertension (72.5\%), hyperlipidemia, and cigarette smoking. The number of cognitive domains with an impairment was highest (in four cognitive tests) among those with coronary artery disease and atrial fibrillation, followed by those who had a $>50 \%$ stenosis in Doppler (three cognitive tests). These findings suggest that the frequency of risk factors associated with stroke does not correlate with the frequency of risk factors associated with cognitive dysfunction. The stroke localizations were classified among the patients with stroke and reviewed in accordance with cognitive impairment.

Conclusion: Neuropsychological tests, clinical findings, and imaging studies should be used to document the poststroke cognitive dysfunction.

Keywords: dementia, vascular dementia, cognitive impairment, neuropsychological assessment, vascular risk factors

\section{Introduction and objective}

Cerebrovascular diseases represent the third leading cause of death and disability. Furthermore, stroke is associated with significant reductions in the quality of life, not only due to the presence of neurological deficits but also due to resultant cognitive dysfunction. $^{2}$

Strokes also represent a major etiological factor for dementia and, accordingly, poststroke dementia (PSD) is considered a subtype of vascular dementia. PSD is defined as the presence of dementia developing within 3 months after an acute, recurring, or initial stroke episode. ${ }^{3}$ Stroke is associated with a 4-12-fold increase in the risk of dementia. ${ }^{4,5}$ The reported PSD prevalence varies between $12.2 \%$ and $31.8 \%$
Correspondence: Talip Asil

Department of Neurology, Faculty of Medicine, Bezmialem Vakıf University, Vatan Caddesi, 34083 İstanbul, Turkey Email talip_asil@yahoo.com 
depending on a number of factors, such as the diagnostic criteria used or the study populations included. ${ }^{4,5}$ Although cognitive dysfunction may be accounted for by the presence of vascular lesions and white matter changes, the underlying neurodegenerative disorders may also contribute to PSD. PSD has a multifactorial pathophysiology, including a number of factors such as advanced age, lower educational status, previous history of stroke, prestroke cognitive dysfunction, diabetes mellitus, myocardial infarction, atrial fibrillation (AF), history of epileptic seizures or sepsis, congestive heart failure, silent cerebral infarction, global lobe or temporal lobe atrophy, or white matter alterations, although the exact mechanisms causing PSD remain unknown. Also, the role of homocysteine as a risk factor in the development of PSD remains a matter of dispute.

In addition to the concept of vascular dementia, another entity referred to as vascular cognitive impairment has been proposed as an umbrella term encompassing all pathological abnormalities due to cerebrovascular conditions resulting in cognitive impairment from mildest cognitive impairment to dementia. ${ }^{6}$

The milder forms of this cognitive impairment include the nondemented vascular cognitive impairment and mild vascular cognitive impairment. ${ }^{7-11}$ While the mild cognitive impairment mainly focuses on memory impairment, nondemented vascular cognitive impairment is not limited to one cognitive domain. Desmond et al ${ }^{12}$ observed delayed improvement between poststroke 3 and 15 months in 10\% of their patients with a mean age of 70 years. In another study involving younger patients, among those with a mild cognitive impairment after stroke, over 30\% had improved cognitive functions between 0 and 6 months, with complete recovery between 12 and 18 months. ${ }^{13}$

Identification of treatable risk factors in PSD has prognostic implications. Also, determination of risk factors for stroke is important for prevention of stroke and PSD. When the risk factors and etiological factors are established, those carrying a risk for the development of PSD may be readily identified and prognostic estimations may be performed. In this regard, it should be borne in mind that not all patients with stroke develop dementia. ${ }^{14}$

With this background, we aimed to examine the development of cognitive impairment after mild ischemic stroke or transient ischemic episodes through the assessment of the frequency of poststroke vascular cognitive dysfunction or PSD, localization of the stroke in patients with vascular cognitive dysfunction or PSD, and the association between cognitive dysfunction and risk factors.

\section{Materials and methods}

This prospective controlled study was carried out at the Neurology Department of the Medical Faculty of Thrace University and patients were selected among those who were admitted with a diagnosis of acute ischemic stroke after the initial assessment at the neurology outpatient unit or emergency room between 2009 and 2011. A total of 40 patients were included in the minor stroke group based on a National Institutes of Health Stroke Scale (NIHSS) score of 5 or less, while similar level of education-, age-, and sexmatched individuals with no vascular or cognitive conditions served as controls $(n=40)$. Patients over 18 years of age with a minimum life expectancy of 1 year who had a transient ischemic stroke or minor stroke within the past 3-month period comprised the target patient population. Whereas, patients $<18$ years with a life expectancy of $<1$ year due to a number of conditions, including malignancy, who had history of hemorrhagic stroke, and an NIHSS score $>5$ with moderate or severe stroke were excluded. Written informed consent was obtained from the patients, and the study was approved by Trakya University Ethics Committee.

At study entry, in addition to NIHSS scores, modified Rankin Scale scores were also obtained. The lesion sites (by applied computed tomography and magnetic resonance scans on patients) were classified according to Oxfordshire Community Stroke Project into the following clinical subtypes: partial anterior circulation infarcts, posterior circulation infarcts, and lacunar infarcts. ${ }^{15}$

Patients were enquired on the presence of risk factors for stroke, including cardiovascular risk factors such as diabetes mellitus, hypertension (HT), coronary artery disease (CAD), and cardiac arrhythmias, as well as for cigarette smoking and hyperlipidemia (HL). Other risk factors were also recorded during history taking and admission. A series of neuropsychological test batteries were used in both patient and control groups to provide a comprehensive cognitive assessment.

The following neuropsychological tests were used for the assessment of cognitive functions: Instrumental Daily Activities of Living for functionality; Mini Mental State Examination (MMSE) for general assessment; forward and backward counting and calculation test for attention; word list memory (can be expressed as flash memory), word list recall (can be expressed as learning period), and word list recognition (can be expressed as recall of knowledge) for the verbal memory; Boston naming test for the language; clock drawing test for planning visuospatial abilities; construction ability for constructing and visual memory (visuospatial functions); and the Frontal Assessment Battery (FAB) for 
executive functions. These tests were readministered at follow-up months 6 and 12 to examine the course of cognitive functions. All neuropsychological tests used were based on Turkuaz Alzheimer Workgroup.

\section{Statistical assessments}

Number Cruncher Statistical System 2007 and PASS 2008 Statistical Software (Kaysville, UT, USA) were used for data analyses. In addition to descriptive statistics (mean, standard deviation, frequency, rate), Student's $t$-test was used for comparisons between the groups for the quantitative data with normal distribution. For detecting the changes in repeated measures, the Variance Analysis for Repeated Measures was used, while Bonferroni test was used for post hoc assessments. The statistical significance was set at a $P$-level $<0.05$.

\section{Results}

A total of 40 patients with a mean age $61.03 \pm 10.75$ years who had minor stroke or tranisent ischemic attack (TIA) enrolled in the study. Forty controls of the same age and sex were recruited into the study. Of the total study population, 30 were female $(37.5 \%)$ and $50(62.5 \%)$ were male (Table 1$)$.

\section{Neuropsychological tests}

A significant worsening in the instrumental scores was detected among patients with stroke within the first month following the incident as compared to controls $(P<0.01)$ (Figure 1). There were no significant changes from baseline in MMSE and forward counting in study groups $(P>0.05)$, while significantly lower scores were obtained in backward counting and calculation skills in patients with stroke $(P<0.01)$ (Figure 2). Although the two groups were comparable in terms of word list recall and word list recognition skills $(P>0.05)$, an assessment of word list memory and overall scores showed significant worsening among patients with stroke than controls $(P<0.01)$ (Figure 3). Abstraction skills were significantly reduced in patients with stroke $(P<0.01)$ (Figure 4). There were no differences in praxis measurements in either group. Clock drawing test results

Table I Demographic characteristics

\begin{tabular}{|c|c|c|c|}
\hline Demographic values & $\begin{array}{l}\text { Patients with } \\
\text { stroke }(n=40)\end{array}$ & $\begin{array}{l}\text { Control subjects } \\
(n=40)\end{array}$ & $P$-value \\
\hline Age, years (mean $\pm S D)$ & $61.03 \pm 10.75$ & $61.03 \pm 10.75$ & 1.000 \\
\hline \multicolumn{4}{|l|}{ Sex, n (\%) } \\
\hline Female & $15(37.5)$ & $15(37.5)$ & 1.000 \\
\hline Male & $25(62.5)$ & $25(62.5)$ & \\
\hline
\end{tabular}

Abbreviation: SD, standard deviation.

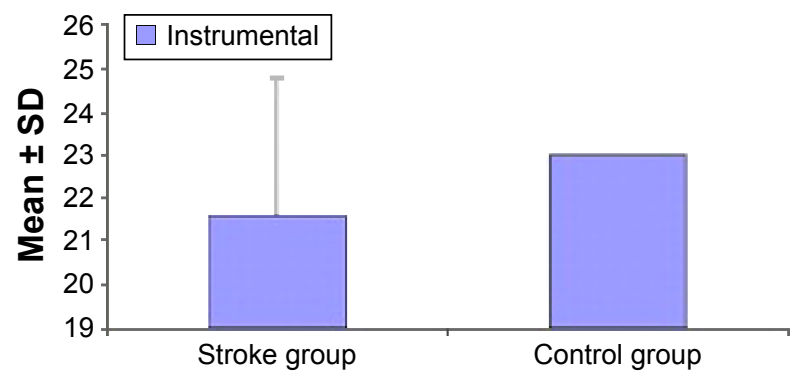

Figure I Instrumental test results at baseline in study groups. Abbreviation: SD, standard deviation.

were similar across the groups ( $P>0.05)$, while significantly lower scores in construction skills, visual memory, and visuospatial functions overall were detected among patients with stroke $(P<0.01)$ (Figure 5). Boston Naming Test results did not differ significantly between the two groups $(P>0.05)$, while $\mathrm{FAB}$ was significantly lower at baseline in patients with stroke $(P<0.01)$ (Figure 6).

With a similar level of education between the two groups, patients with stroke exhibited significant worsening in the majority of neuropsychological tests and experienced impairment in many cognitive domains after minor stroke as compared to control group.

A significant improvement from baseline (month 0 ) to 6 months and from baseline to 12 months was observed in the results of neuropsychological tests. Although no significant improvement occurred in other tests, there was also no worsening in any of these test batteries except for the calculation skills (Figure 7). The majority of the patients had a stable clinical course.

\section{Risk factors}

Risk factors most frequently detected in our patients with minor stroke include HT (72.5\%), HL, and smoking. HT, $\mathrm{HL}$, diabetes mellitus, smoking, $\mathrm{CAD}$, and $\mathrm{AF}$ were presented in $72.5 \%(\mathrm{n}=29), 67.5 \%(\mathrm{n}=27), 25 \%(\mathrm{n}=10), 60 \%(\mathrm{n}=24)$, $15 \%(\mathrm{n}=6)$, and $22.5 \%(\mathrm{n}=9)$ of the patients, respectively (Figure 8).

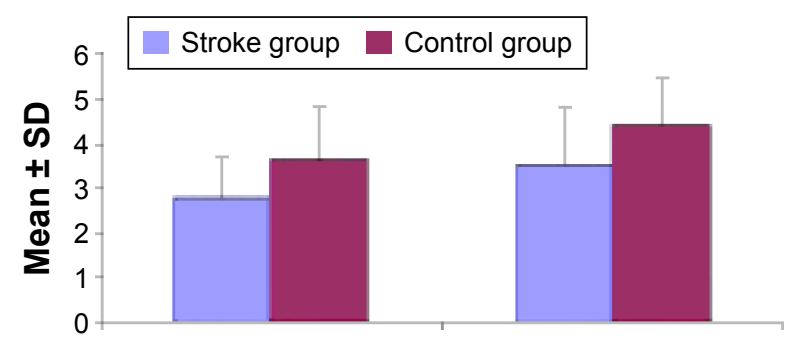

Figure 2 Backward counting and calculation test results in study groups at baseline (attention).

Abbreviation: SD, standard deviation. 


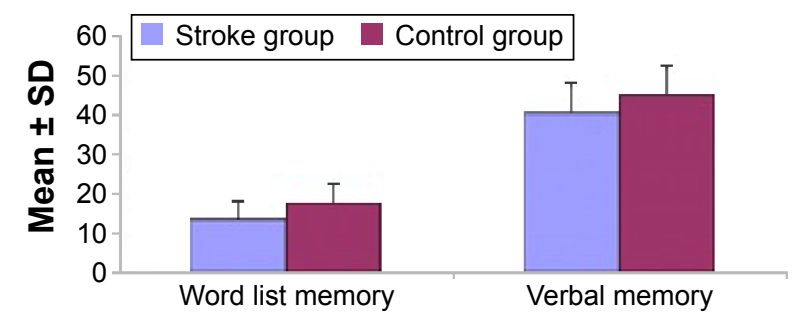

Figure 3 Word list memory and verbal memory test results in study groups at baseline.

Abbreviation: SD, standard deviation.

Most severe cognitive impairment (ie, in four cognitive tests) was seen among those with $\mathrm{CAD}$ and $\mathrm{AF}$, followed by patients with $>50 \%$ stenosis in Doppler examination who had relatively less severe impairment (ie, in three cognitive tests), suggesting that the frequency of risk factors for stroke does not correlate with the frequency of risk factors associated with cognitive impairment.

Of our patient population, $70 \%$ had internal carotid artery stenosis of $<50 \%$ and $30 \%$ had a stenosis $>50 \%$. As expected, those with an internal carotid artery stenosis $>50 \%$ had greater impairment.

Although cigarette smoking was a risk factor, it was associated with only a minimal increase in the occurrence of cognitive deficits as compared to nonsmokers.

Upon evaluation of impairment ratios in cognitive tests as per risk factors, an improvement occurred in at least one of the cognitive tests.

Except for AF, an improvement was observed in backward counting in all risk factor strata. Also, independent of the risk factors, a significant improvement occurred at 6 and 12 months as compared to baseline among the study patients. Among these patients, it was observed that patients with $\mathrm{AF}$ and coronary artery disease (CAH) were not included in the group in which significant improvement occurred (Table 2).

The cognitive functions that were most frequently affected among hypertensive patients included word list

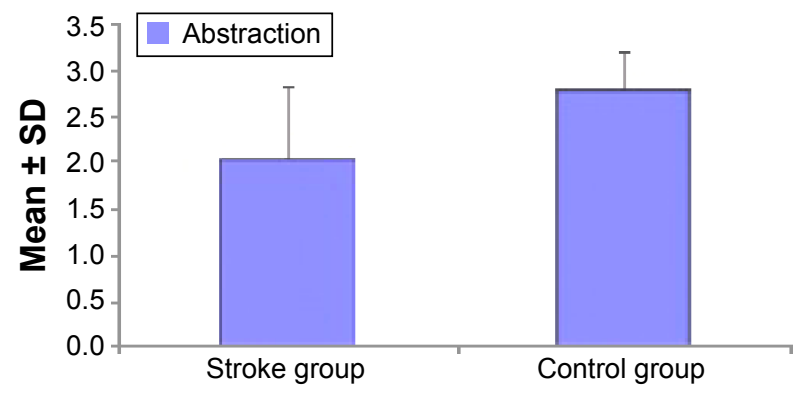

Figure 4 Abstraction test results in study groups at baseline. Abbreviation: SD, standard deviation.

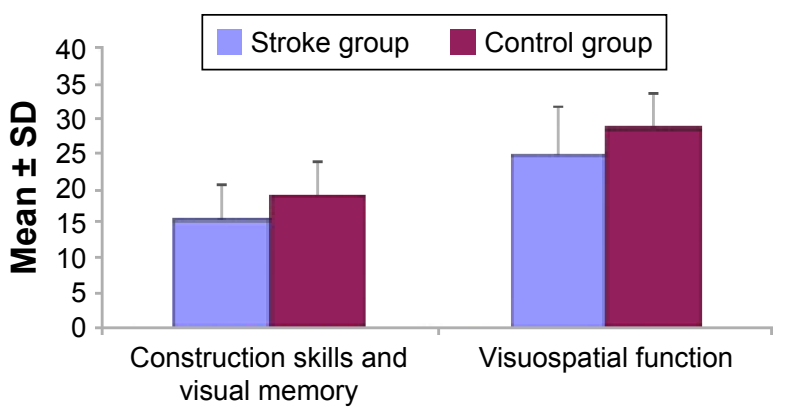

Figure 5 Construction skills and visual memory and visuospatial function results in study groups at baseline.

Abbreviation: SD, standard deviation.

memory, FAB test, and backward counting. Hypertensive individuals did not suffer from significant impairment of executive functions as shown by the FAB test.

Radiological findings in study patients included periventricular leukoaraiosis in seven, global atrophy in 14, and temporal atrophy in one patient (Table 3). The three tests that were most frequently affected among patients with periventricular leukoaraiosis included the FAB test, measuring the frontal executive functions, as well as construction skills and word list memory.

Eight patients had anterior stroke, nine had posterior, and seven had lacunar strokes; also, nine patients had transient ischemic episode, and seven patients had anterior and posterior stroke. For study purposes, thalamic infarcts were classified in the category of lacunar infarcts, which were associated with impairment in all tests, except for word list recall and word list recognition. The most frequently affected tests in patients with lacunar infarcts included the word list memory, backward counting, calculation, and FAB.

There were 17 and 15 patients with right or left hemispheric lesions, respectively; a single patient had both right and left hemispheric lesions, while seven patients had no signs of lateralization. Patients with left hemispheric lesions had higher frequency of impairment in all tests as compared

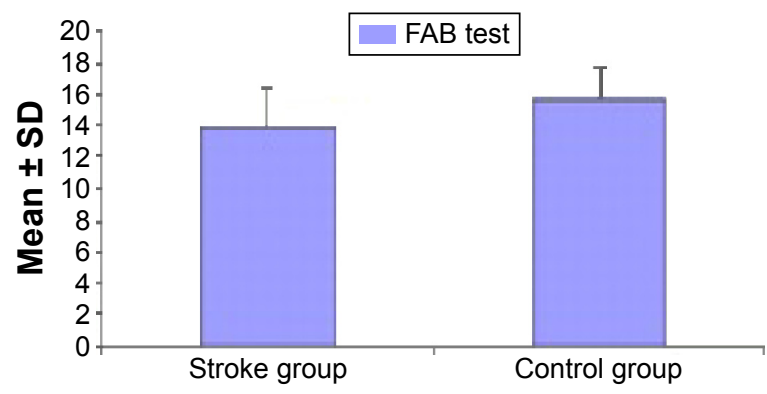

Figure 6 FAB test results in study groups at baseline. Abbreviations: FAB, Frontal Assessment Battery; SD, standard deviation. 


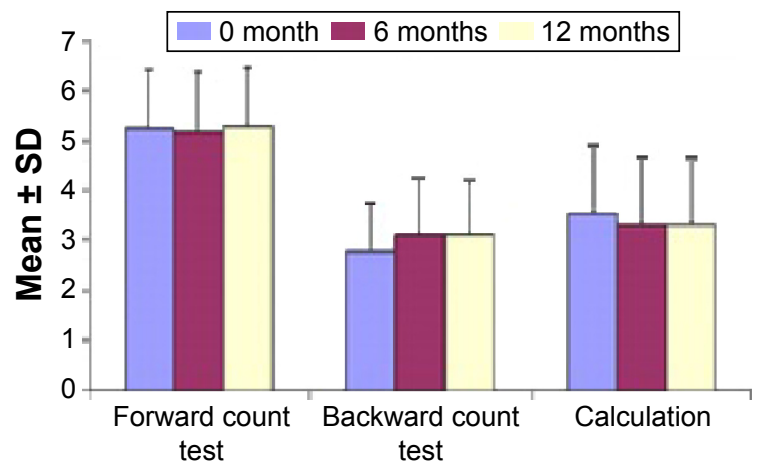

Figure 7 Forward counting, backward counting, and calculation test results in the stroke group.

Abbreviation: SD, standard deviation.

to those with right hemispheric lesions. Also, from a clinical viewpoint, patients with left hemispheric lesions had minimal impairment in abstraction, while those with right hemispheric lesions had minimal impairment in executive functions as documented by clock drawing and FAB tests.

A minor stroke occurring over 70 years of age was associated with a more marked cognitive impairment in all test categories as compared to those $<70$ years of age. This difference was statistically significant (Table 4).

\section{Discussion}

Cerebrovascular diseases may lead to significant reductions in the quality of life, not only due to the associated neurologic deficits but also due to the development of subsequent cognitive dysfunction. Identification and prevention of cerebrovascular events and the associated risk factors carry even a greater significance than the cognitive deficits resulting in decreased functionality.

The conclusions of the current study examining the identification and subsequent course of cognitive functions in patients with minor stroke and transient ischemic attack are described later. An assessment of the association between

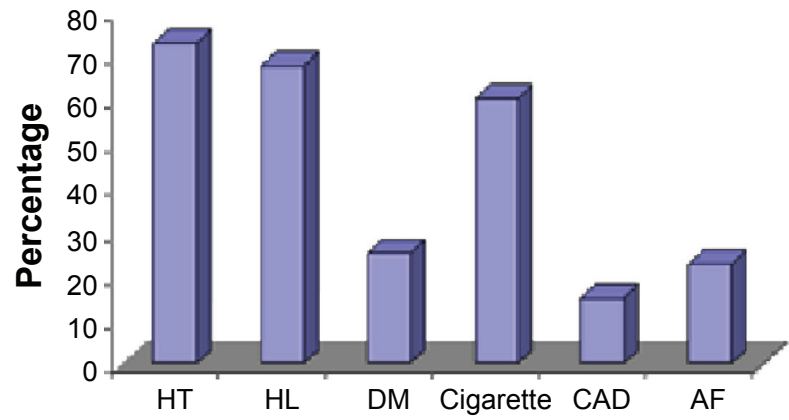

Figure 8 Distribution of risk factors in the stroke group $(n=40)$. Abbreviations: $A F$, atrial fibrillation; $C A D$, coronary artery disease; $D M$, diabetes mellitus; HL, hyperlipidemia; HT, hypertension. cognitive decline and risk factors following a minor stroke showed comparable and highest rates of cognitive impairment in patients with $\mathrm{CAD}$ and $\mathrm{AF}$ (highest cognitive impairment in four of the overall cognitive test battery). Patients over 70 years of age had more marked cognitive impairment in all cognitive tests as compared to those $<70$ years of age. Also, patients with left hemispheric lesions had more marked impairment in all tests as compared to those with right hemispheric lesions. In comparison with educationally matched controls, patients had significantly more marked impairment in the majority of the neuropsychological tests, and assessment of the results of the neuropsychological tests at early phase and 6 months showed a significant improvement only in the backward counting. Despite the absence of a significant improvement in other tests, there was also no worsening in any of the other tests except for the calculation tests. Most patients had a clinically stable course.

\section{Cognitive test results according to risk factors}

The most common risk factors in our study population were HT (72.5\%), HL, and cigarette smoking. However, an assessment of the association between risk factors and cognitive impairment following minor strokes showed highest and similar rates of cognitive dysfunction in those with CAD and AF (most severe impairment in four of all cognitive tests). These were followed by the group of patients who had $>40 \%$ stenosis in Doppler examination (most severe impairment in three of all cognitive tests). These observations suggest the absence of a correlation between the frequency of risk factors for stroke and risk factors for cognitive dysfunction. Also, when the etiological role of AF in the development of stroke is considered, it seems that examination of the cognitive deficits may bear clinical significance in those with cardioembolic stroke.

HT is an important risk factor for cerebrovascular diseases, also with significant roles in the development of vascular cognitive dysfunction and vascular dementia. ${ }^{16}$ The association among HT, low blood flow rates, and vascular dementia has been clearly established. ${ }^{17,18}$ Studies suggest that blood pressure should be maintained below $140 / 90 \mathrm{mmHg}$ to provide protection against cardiovascular and cerebrovascular diseases and certain types of dementia, as well as for the maintenance adequate cognition in the long-term. ${ }^{18}$ Longitudinal studies suggested that HT in the middle age may be associated with cognitive dysfunction developing in later stages of life. ${ }^{17}$ Kuo et a ${ }^{19}{ }^{19}$ in their 2004 study claimed that high blood pressure in otherwise healthy 
Table 2 Risk factors affecting the backward counting skill

\begin{tabular}{lllll}
\hline & \multicolumn{4}{l}{ Number of patients who had disturbance of backward counting skill } \\
\cline { 2 - 5 } & Initial (\%) & 6 months (\%) & I2 months (\%) & P-values \\
\hline HT $(\mathrm{N}=29)$ & $25(82.2)$ & $23(79.3)$ & $23(79.3)$ & 0.028 \\
DM $(\mathrm{N}=10)$ & $9(90)$ & $8(80)$ & $8(80)$ & 0.134 \\
Smoker (N=24) & $18(75)$ & $17(70.8)$ & $17(70.8)$ & 0.059 \\
Hypercholesterolemia $(\mathrm{N}=27)$ & $22(81.5)$ & $19(70.4)$ & $19(70.4)$ & 0.031 \\
Coronary artery disease $(\mathrm{N}=6)$ & $6(100)$ & $6(100)$ & $6(100)$ & 0.363 \\
Atrial fibrillation $(\mathrm{N}=9)$ & $7(77.8)$ & $7(77.8)$ & $7(77.8)$ & 0.390 \\
\hline
\end{tabular}

Abbreviations: DM, diabetes mellitus; HT, hypertension.

individuals could be associated with selective impairment of executive functions.

In a study by Khedr et al, ${ }^{14} \mathrm{AF}$ was more common among patients with PSD, although no significant association with PSD could be established. On the other hand, in 2000, Barba et $\mathrm{al}^{1}$ found correlations between cognitive decline and AF. AF not only may result in thromboembolic events but also leads to reduced cardiac output, which is more marked in higher ventricular rates, potentially leading to cerebral hypoperfusion. This may also represent an additional mechanism contributing to the development of brain injury and cognitive decline. ${ }^{20}$

In our study, $70 \%$ of the patients had a carotid stenosis of $<50 \%$, while stenosis was $\geq 50 \%$ in the remaining $30 \%$, with the latter group having more frequent occurrence of cognitive impairment as documented by the cognitive tests. Carotid stenosis, one of the risk factors for such conditions, is a common occurrence in patients with PSD, although no

Table 3 The distribution of site and clinical signs in patients with stroke

\begin{tabular}{lll}
\hline $\begin{array}{l}\text { Stroke type and } \\
\text { symptoms }\end{array}$ & \multicolumn{2}{l}{$\begin{array}{l}\text { Patients with stroke } \\
(\mathbf{n}=\mathbf{4 0})\end{array}$} \\
\cline { 2 - 3 } & $\mathbf{n}$ & $\%$ \\
\hline Ischemic stroke & & \\
$\quad$ Anterior & 8 & 20.0 \\
Posterior & 9 & 22.5 \\
Lacunar & 7 & 17.5 \\
Transient ischemic attack & 9 & 22.5 \\
Anterior + posterior & 7 & 17.5 \\
Side involved & & \\
None & 7 & 17.5 \\
Right & 17 & 42.5 \\
Left & 15 & 37.5 \\
Right and left & 1 & 2.5 \\
Aphasia & 0 & 0 \\
Dysarthria & 20 & 50.0 \\
Visual defects & 4 & 10.0 \\
Motor defects & 22 & 55.0 \\
Sensory defects & 10 & 25.0 \\
\hline
\end{tabular}

significant associations could be established between the severity of stenosis and cognitive decline. ${ }^{3}$ In some recent studies, common carotid artery intima-media thickness was identified as a risk factor for deficits in memory and cognition, particularly among the elderly females. ${ }^{21}$ Talelli et $\mathrm{al}^{22}$ failed to observe a significant association between common carotid artery intima-media thickness and cognitive decline 12 months after an ischemic stroke when other risk factors were adjusted. Lee and $\mathrm{Yeh}^{23}$ observed a better level of cognition among patients with lower common carotid artery intima-media thickness, as assessed by Cognitive Abilities Screening Instrument. In 2009, Wendell et al ${ }^{24}$ found impaired cognitive functions in healthy subjects with increased carotid media thickness. In line with the observations by Wendell et al, ${ }^{24}$ this result suggests that the severity of cognitive dysfunction increases with increasing stenosis.

In the present study, a more marked cognitive impairment was found in all tests among patients over 70 years of age as compared to those $<70$ years of age, consistent with previous observations suggesting that advanced age represents a significant risk factor for cognitive deficits.

Also, more patients with left hemispheric lesions had cognitive impairment in all cognitive assessment tools than patients with right hemispheric lesions. Also, bilateral infarcts and more extensive involvement of the dominant hemisphere were found to increase the risk of dementia in patients with

Table 4 Cognitive disturbance according to age group

\begin{tabular}{|c|c|c|c|}
\hline \multirow[t]{3}{*}{ Time } & \multicolumn{2}{|c|}{$\begin{array}{l}\text { Number of defective cognitive } \\
\text { items }\end{array}$} & \multirow[t]{3}{*}{$P$-values } \\
\hline & $\leq 70$ years age & $>70$ years age & \\
\hline & Mean \pm SD & Mean \pm SD & \\
\hline 0 month & $5.86 \pm 2.44(5)$ & $7.91 \pm 2.70(9)$ & $0.042 *$ \\
\hline 6 months & $5.86 \pm 2.23$ & $8.00 \pm 2.54(8)$ & $0.026 *$ \\
\hline 12 months & $5.86 \pm 2.24(5)$ & $7.90 \pm 2.55$ (8) & $0.027 *$ \\
\hline
\end{tabular}

Note: $* P<0.05$

Abbreviation: SD, standard deviation. 
stroke patients who were diagnosed with vascular dementia both radiologically and pathologically. ${ }^{25}$

\section{Detailed assessment of the cognitive tests}

Comparison of patients and controls in our study during the early phase revealed significant impairment in attention (backward counting), visuospatial functions (construction skills and visual memory), language (word list memory), calculation, and abstraction, as well as in all executive function domains in the patient group. Srikanth et al ${ }^{26}$ utilized similar neuropsychological tests, similar timing of tests as well as a similar stroke classification, while in contrast with our study, they also involved patients with intracerebral hemorrhage. In this study, the patient group had significant impairment in attention, visuospatial functions, language, and executive functions as compared to controls, while the impairment in memory was less severe.

All patients with minor stroke or transient ischemia in our study had impaired FAB test results for frontal executive functions. Although verbal memory scores were low among the overall group of patients with vascular cognitive impairment and vascular dementia, their performance in word list recall and recognition was not significantly different from that in controls. ${ }^{27}$ Again, Sachdev et a ${ }^{28}$ showed that impaired frontal executive functions and psychomotor retardation represent two prominent areas of involvement in vascular cognitive impairment and vascular dementia. Also, dominant and nondominant parietal lobe functions are affected.

In our group of hypertensive patients, the most frequently affected cognitive functions were word list memory, FAB (frontal executive functions), backward counting, and attention. Thus, executive dysfunction was also a marked characteristic in these hypertensive individuals.

The three tests that were most frequently affected among patients with periventricular leukoaraiosis included the FAB test, measuring the frontal executive functions, as well as construction skills and word list memory. Foci of white matter in the periventricular and subcortical regions have been associated with memory and executive functions. ${ }^{29-31}$

Our patients with posterior infarcts had, in the decreasing order of severity, impairment in memory, executive functions, and attention. Cerebellar pathological conditions are generally associated with less severe cognitive dysfunction. In a case report by Paulus et al, ${ }^{32}$ impairment in attention, executive functions, and memory were observed in a patient with a large cerebellar infarct. This patient without motor dysfunction was diagnosed as having a pure cerebellar cognitive affective syndrome.
In the current study, thalamic infarcts were categorized within the class of lacunar infarcts, which were found to be associated with impairments in all tests except for word list recall and word list recognition. In other words, these patients had impairment in attention, concentration, and verbal and visual memory. The tests that were most frequently impaired included word list memory, backward counting, calculation, and FAB. While the word list memory was the most frequently involved area of impairment, no finding of disturbance in word list recall and recognition suggested that the cognitive decline in thalamic (lacunar) infarcts leads to a learning difficulty rather than a recall problem.

Thalamic infarcts also represent a significant cause of cognitive deficits, and amnesia developing in association with thalamic infarcts leads to learning difficulties rather than recall problems. Ischemic lesions involving the mammillothalamic tract in the tuberothalamic artery zone cause learning and short-term memory deficits. Aphatia and abulia generally occur in those with anterior thalamic pedincle. ${ }^{33}$ Szirmai et al ${ }^{13}$ studied 19 patients with thalamic infarction and demonstrated that there were deficits in attention, concentration, visual and verbal deficits in patients with left or bilateral thalamic infarction. Paramedian lesions of the thalamus may lead to naming difficulty or perseverations, although cortical aphasia does not occur. ${ }^{35}$ Since the medial dorsal nucleus is connected with Broca's and Wernicke's areas, a variety of language problems may emerge. Szirmai et $\mathrm{al}^{34}$ found an increased incidence of semantic and verbal disturbances when thalamic lesions occurred in association with striatocapsular infarcts.

\section{An assessment of the prognosis during follow-up}

In the present study, $22.5 \%$ of the patients had impairment in a maximum of five test categories at baseline, and similarly at 6 months, $22.5 \%$ of the patients had impairment in five tests, while at 12 months, $17.5 \%$ had impairment in five tests. The number of tests with impairment decreased from baseline to 12 months, although the difference was not significant. The number of cognitive tests (13 in total) with impairment did not alter significantly during the follow-up period, that is, from 0 to 6,0 to 12 , and 6 to 12 months, suggesting a stable clinical course in the majority of the patients.

Tham et $\mathrm{al}^{13}$ assessed attention, language, verbal memory, visual memory, visual construction, and visual-motor velocity at baseline and at 6 months in patients enduring transient ischemic attack without permanent disability and found that $56 \%$ of the patients had normal cognition 
at baseline, while $40 \%$ had cognitive impairment without dementia, and 4\% had dementia. At 1 year, cognitive disorders in $31 \%$ of patients had improved, but cognitive impairment occurred in $10 \%$ of patients with initial normal cognitive performance, and dementia occurred in $11 \%$ of patients who had mild cognitive impairments. These results point out to a long-term variability between patients in terms of the results of cognitive performance tests. In spite of the reports suggesting considerable cognitive dysfunction (ie, 18\%-26\%) 3 months after stroke, Rasquin et $\mathrm{al}^{36}$ in their study assessing poststroke memory, mental speed, and executive functions reported that $12 \%$ of the patients developed dementia within 1 year. ${ }^{37-39}$ Again in the same study, an improvement rather than worsening in cognitive performance was noted between 1 and 6 months.

An examination of the rate of improvement according to risk factor in our study showed that there was an improvement in at least one cognitive test. Except for patients with AF, backward counting improved in all other risk groups. Also, a statistically significant improvement in backward counting occurred from baseline (month 0 ) to 6 and 12 months in the patient group, regardless of the risk factors. Patients with AF, however, did not belong to the group in which significant improvement occurred.

Neuropsychological tests administered at baseline and 6 months showed a significant improvement only in backward counting test between 0 and 6 and 0 and 12 months. Despite the absence of significant improvement in other tests, no significant worsening occurred also, except for the calculation test.

Also, there was an improvement in MMSE scores between 0 and 6 months, although this was not significant. In a study from Israel, patients with lacunar infarcts had an average decline of 1.1 point in MMSE scores. ${ }^{40}$ In another study involving elderly patients with vascular dementia, a 1.77 point decrease occurred in MMSE scores at the end of 1 year of follow-up. ${ }^{41}$

In a study by Ballard et al, ${ }^{42}$ patients $\geq 75$ years of age were examined 3 and 15 months poststroke. $\mathrm{A} \geq 2$ point increase in MMSE was considered to indicate cognitive improvement, while development of dementia according to Diagnostic and Statistical Manual of Mental Disorders - 4th Edition was considered cognitive decline; patients without such changes were considered stable. Among these patients, those with diabetes were less likely to be represented in the group with improvement in cognitive functions.

Accordingly, Srikanth et $\mathrm{al}^{43}$ found no increase in progressive dementia risk in mild to moderately severe stroke patients without aphasia, provided that stroke does not recur.

\section{Study limitations}

Several studies found an association between the severity of stroke and increased risk of dementia, ${ }^{1,3,37,44-47}$ with suggestion of a higher risk for extensive dominant hemispheric lesions..$^{3,37,45}$ In our study, patients with severe strokes, particularly those with total anterior circulation infarcts, were excluded. As inclusion criteria in the study were using the NIHS score, infarct volume in cranial imaging was not measured.

In our study, all patients with minor stroke or transient ischemic episode had impairment in at least two of the neuropsychological tests administered. Possible explanations of the higher rate of impairment compared to previous reports include a detailed examination of the results of a variety of cognitive tests, exclusion of memory disturbance as a study criteria, and small sample size.

Cognitive tests proposed by Turkuaz Alzheimer Working group were used in our study. Addition of a depression scale to those already utilized could have provided a more comprehensive patient assessment.

Further prospective studies examining the total brain volume or infarct volume in larger patient populations and the use of appropriate neuropsychological assessments will prove valuable in the follow-up of these patients.

\section{Conclusion}

In patients with vascular dementia, disturbance in other cognitive domains far precedes the disturbance in memory. Recognition of cognitive disturbance may allow earlier diagnosis and treatment of vascular dementia before advanced vascular dementia develops. This, in turn, may help offset the limitations of preventive therapeutic strategies.

\section{Disclosure}

The authors report no conflicts of interest in this work.

\section{References}

1. Barba R, Martinez ES, Rodriguez GE, Pondal M, Vivancos J, Del Ser T. Poststroke dementia: clinical features and risk factors. Stroke. 2000;31:1494-1501.

2. De Haan RJ, Limburg M, Van Der Meulen JH, Jacobs HM, Aaronson NK. Quality of life after stroke. Impact of stroke type and lesion location. Stroke. 1995;26:402-408.

3. Pohjasvaara T, Erkinjuntti T, Yilkoski R, Hietanen M, Vataja R, Kaste M. Clinical determinants of poststroke dementia. Stroke. 1998;29:75-81.

4. Tatemichi TK, Paik M, Bagiella E, et al. Risk of dementia after stroke in a hospitalized cohort: results of a longitudinal study. Neurology. 1994; 44:1885-1891. 
5. Leys D, Henon H, Mackowiak-Cordoliani MA, Pasquier F. Poststroke dementia. Lancet Neurol. 2005;4:752-759.

6. O’Brien JH, Erkinjuntti T, Reisberg B, et al. Vascular cognitive impairment. Lancet Neurol. 2003;2:89-98.

7. Frisoni GB, Galluzzi S, Bresciani L, Zanetti O, Geroldi C. Mild cognitive impairment with subcortical vascular features. Clinical characteristics and outcome. J Neurol. 2002;249:1423-1432.

8. Ebly EM, Hogan DB, Parhad IM. Cognitive impairment in the nondemented elderly. Results from the Canadian Study of Health and Aging. Arch Neurol. 1995;52:612-619.

9. Ingles JL, Wentzel C, Fisk JD, Rockwood K. Neuropsychological predictors of incident dementia in patients with vascular cognitive impairment, without dementia. Stroke. 2002;33:1999-2002.

10. Wentzel C, Rockwood K, MacKnight C, et al. Progression of impairment in patients with vascular cognitive impairment without dementia. Neurology. 2001;57:714-716.

11. Petersen RC, Smith GE, Waring SC, Ivnik RJ, Tangalos EG, Kokmen E. Mild cognitive impairment: clinical characterization and outcome. Arch Neurol. 1999;56:303-308.

12. Desmond DW, Moroney JT, Sano M, Stern Y. Recovery of cognitive function after stroke. Stroke. 1996;27:1798-1803.

13. Tham W, Auchus AP, Thong M, et al. Progression of cognitive impairment after stroke: one year results from a longitudinal study of Singaporean stroke patients. J Neurol Sci. 2002;203-204:49-52.

14. Khedr EM, Hamed SA, El-Shereef HK, et al. Cognitive impairment after cerebrovascular stroke: relationship to vascular risk factors. Neuropsychiatr Dis Treat. 2009;5:103-116.

15. Madureira S, Guerreiro M, Ferro JM. Dementia and cognitive impairment three months after stroke. Eur J Neurol. 2001;8:621-627.

16. In't Veld BA, Ruitenberg A, Hofman A, Stricker BA, Breteler MMB. Antihypertensive drugs and incidence of dementia: the Rotterdam Study. Neurobiol Aging. 2001;22:4071.

17. Harrington F, Saxby BK, McKeith IG, Wesnes K, Ford GA. Cognitive performance in hypertensive and normotensive older subjects. Hypertension. 2000;36:1079-1082.

18. Birkenhager WH, Forette F, Seux ML, Wang JG, Staessen JA. Blood pressure, cognitive functions, and prevention of dementias in older patients with hypertension. Arch Intern Med. 2001;161:152-156.

19. Kuo H-K, Sorond F, Iloputaife I, Gagnon M, Milberg W, Lipsitz LA. Effect of blood pressure on cognitive functions in elderly persons. J Gerontol A Biol Sci Med Sci. 2004;59(11):1191-1194.

20. Ott A, Breteler MM, de Bruyne MC, van Harskamp F, Grobbee DE, Hofman A. Atrial fibrillation and dementia in a population-based study. The Rotterdam Study. Stroke. 1997;28:316-321.

21. Komulainen P, Kivipelto M, Lakka TA, et al. Carotid intima-media thickness and cognitive function in elderly women: a population-based study. Neuroepidemiology. 2007;28:207-213.

22. Talelli P, Ellul J, Terzis G, et al. Common carotid artery intima media thickness and post-stroke cognitive impairment. J Neurol Sci. 2004;223: 129-134.

23. Lee YH, Yeh SJ. Correlation of common carotid artery intima media thickness, intracranial arterial stenosis and post-stroke cognitive impairment. Acta Neurol Taiwan. 2007;16:207-213.

24. Wendell CR, Zonderman AB, Metter EJ, Najjar SS, Waldstein SR. Carotid intimal medial thickness predicts cognitive decline among adults without clinical vascular disease. Stroke. 2009;40(10):3180-3185.

25. Jayakumar PN, Taly AB, Shanmugam V. Multi-infarct dementia: a computed tomographic study. Acta Neurol Scand. 1989;73:292-295.

26. Srikanth VK, Thrift AG, Saling MM, et al; Community-Based Prospective Study of Nonaphasic English-Speaking Survivors. Increased risk of cognitive impairment 3 months after mild to moderate first-ever stroke: a community-based prospective study of nonaphasic English-speaking survivors. Stroke. 2003;34:1136-1143.
27. Grober E, Kawas C. Learning and retention in preclinical and early Alzheimer's disease. Psychol Aging. 1997;12:183-188.

28. Sachdev PS, Brodaty H, Valenzuela MJ, et al. The neuropsychological profile of vascular cognitive impairment in stroke and TIA patients. Neurology. 2004;62:912-919.

29. De Groot JC, De Leeuw FE, Oudkerk M, Hofman A, Jolles J, Breteler MM. Cerebral white matter lesions and depressive symptoms in elderly adults. Arch Gen Psychiatry. 2000;57:1071-1076.

30. Gunning-Dixon FM, Raz N. The cognitive correlates of white matter abnormalities in normal aging: a quantitative review. Neuropsychology. 2000;14:224-232.

31. Kramer-Ginsberg E, Greenwald BS, Krishnan KR, et al. Neuropsychological functioning and MRI signal hyperintensities in geriatric depression. Am J Psychiatry. 1999;156:438.

32. Paulus KS, Magnano I, Conti M, et al. Pure post-stroke cerebellar cognitive affective syndrome: a case report. Neurol Sci. 2004;25:220-224.

33. Bhatia KP, Marsden CD. The behavioral and motor consequences of focal lesions of the basal ganglia in man. Brain. 1994;117:859-876.

34. Szirmai I, Vastagh I, Szombathelyi E, Kamondi A. Strategic infarcts of the thalamus in vascular dementia. Neurol Sci. 2002;203-204:91-97.

35. Stuss DT, Guberman A, Nelson R, Larochelle S. The neuropsychology of paramedian thalamic infarction. Brain Cogn. 1988;8:348-378.

36. Rasquin SM, van Oosstenbruge RJ, Verhey FR, Lodder J. Vascular mild cognitive impairment is highly prevalant after lacunar stroke but does not increase over time: a 2 year follow up study. Dement Geriatr Cogn Disorder. 2007;24:396-401.

37. Desmond DW, Moroney JT, Paik MC, et al. Frequency and clinical determinants of dementia after ischemic stroke. Neurology. 2000;54: 1124-1131.

38. Pohjasvaara T, Erkinjuntti T, Vataja R, Kaste M. Dementia three months after stroke: baseline frequency and effect of different definitions of dementia in the Helsinki Stroke Aging Memory Study (SAM) cohort. Stroke. 1997;28:785-792.

39. Tatemichi TK, Desmond DW, Mayeux R, et al. Dementia after stroke: baseline frequency, risks and clinical features in a hospitalized cohort. Neurology. 1992;42:1185-1193.

40. Aharon-Peretz J, Daskovski E, Mashiach T, Tomer R. Natural history of dementia associated with lacunar infarctions. JNeurol Sci. 2002;203-204: 53-55.

41. Segal-Gidan FI, Lyness SA, Chui HC. A comparison of mental status decline in ischemic vascular dementia and Alzheimer's disease. Neurology. 1999;52(suppl 2):486-487.

42. Ballard C, Stephens S, Kenny R, Kalaria R, Tovee M, O'Brien J. Profile of neuropsychological deficits in older stroke survivors without dementia. Dement Geriatr Cogn Disord. 2003;16:52-56.

43. Srikanth VK, Anderson JFI, Donnan GA, et al. Progressive dementia after first ever stroke: a community-based follow-up study. Neurology. 2004;63:785-792.

44. Censori B, Manara O, Agostinis C, et al. Dementia after first stroke. Stroke. 1996;27:1205-1210.

45. Tatemichi TK, Desmond DW, Paik M, et al. Clinical determinants of dementia related to stroke. Ann Neurol. 1993;33:568-575.

46. Henon H, Durieu I, Guerouaou D, Lebert F, Pasquier F, Leys D. Poststroke dementia: incidence and relationship to prestroke cognitive decline. Neurology. 2001;57:1216-1222.

47. Inzitari D, Di Carlo A, Pracucci G, et al. Incidence and determinants of poststroke dementia as defined by an informant interview method in a hospital-based stroke registry. Stroke. 1998;29:2087-2093. 


\section{Publish your work in this journal}

Neuropsychiatric Disease and Treatment is an international, peerreviewed journal of clinical therapeutics and pharmacology focusing on concise rapid reporting of clinical or pre-clinical studies on a range of neuropsychiatric and neurological disorders. This journal is indexed on PubMed Central, the 'PsycINFO' database and CAS,

and is the official journal of The International Neuropsychiatric Association (INA). The manuscript management system is completely online and includes a very quick and fair peer-review system, which is all easy to use. Visit http://www.dovepress.com/testimonials.php to read real quotes from published authors.

Submit your manuscript here: http://www.dovepress.com/neuropsychiatric-disease-and-treatment-journal 